\title{
Effect of Gender on Outcome of Out of Hospital Cardiac Arrest in the Resuscitation
}

\section{Outcomes Consortium}

Laurie J. Morrison MD, MSc ${ }^{1-3}$, Robert H. Schmicker MSc ${ }^{4}$, Myron L. Weisfeldt MD ${ }^{5}$, Blair L.

Bigham MD, MSc ACP ${ }^{1}$, Robert A. Berg, $\mathrm{MD}^{6}$, Alexis A. Topjian, MD, $\mathrm{MSc}^{6}$, Beth L.

Abramson MD, $\mathrm{MSc}^{7}$, Dianne L. Atkins $\mathrm{MD}^{8}$, Debra Egan ${ }^{9}$, George Sopko ${ }^{9}$, Valeria E. Rac

$\mathrm{MD}, \mathrm{PhD}^{3,10}$, and the Resuscitation Outcomes Consortium Investigators.

${ }^{1}$ Rescu, Li Ka Shing Knowledge Institute, St. Michael's Hospital, University of Toronto, Toronto, Ontario, Canada

${ }^{2}$ Division of Emergency Medicine; Department of Medicine, University of Toronto, Toronto, Ontario, Canada

${ }^{3}$ Institute of Health Policy, Management \& Evaluation, University of Toronto, Toronto, Ontario, Canada

${ }^{4}$ Clinical Trials Center, University of Washington, WA, USA

${ }^{5}$ Johns Hopkins Medicine. Baltimore, MD, USA

${ }^{6}$ The Children's Hospital of Philadelphia, University of Pennsylvania School of Medicine, Philadelphia, PA, USA

${ }^{7}$ Cardiac Prevention Centre \& Women's Cardiovascular Health, St. Michael's Hospital, University of Toronto, Toronto, Ontario, Canada

${ }^{8}$ University of Iowa Children's Hospital, Carver College of Medicine, Iowa City, IA, USA of Iowa Children's Hospital, Iowa City, IA, USA

${ }^{9}$ Division of Cardiovascular Diseases, National Heart, Lung and Blood Institute, National Institutes of Health, Bethesda, MD, USA

${ }^{10}$ Toronto Health Economics and Technology Assessment Collaborative, Toronto General Research Insitute, University Health Network, and Leslie Dan Faculty of Pharmacy, University of Toronto, Toronto, Ontario, Canada

*Corresponding author

Laurie J. Morrison: Rescu, St. Michael's Hospital, 30 Bond Street, Toronto, Ontario, Canada

M5B 1W8 Tel: (416) 864-6060 ext. 7842 Fax: (416) 864-5934

E-mail address: morrisonl@smh.ca

\section{Word count: 2142}


Abstract 245

Introduction

This study examined the relationship between gender and outcomes of non-traumatic out-ofhospital cardiac arrest (OHCA).

\section{Methods}

All eligible, consecutive, non-traumatic Emergency Medical Services (EMS) treated OHCA patients in the Resuscitation Outcomes Consortium between December 2005 and May 2007. Patient age was analyzed as a continuous variable and stratified in two age cohorts: 15-45 and $>55$ years of age (yo). Unadjusted and adjusted (based on Utstein characteristics) chi square tests and logistic regression models were employed to examine the relationship between gender, age and survival outcomes.

\section{Results}

This study enrolled 14,690 patients: of which $36.4 \%$ were women with a mean age of 68.3 and $63.6 \%$ of them men with a mean age of 64.2 . Women survived to hospital discharge less often than men $(6.4 \%$ vs. $9.1 \%, \mathrm{p}<0.001)$; the unadjusted OR was $0.69,95 \% \mathrm{CI}: 0.60,0.77$ whereas when adjusted for all Utstein predictors the difference was not significant (OR: 1.16, 95\%CI: $0.98,1.36, \mathrm{p}=0.07)$. The adjusted survival rate for younger women $(15-45$ yo) was $11.1 \%$ vs. $9.8 \%$ for younger men (OR: $1.66,95 \% \mathrm{CI}: 1.04,2.64, \mathrm{p}=0.03)$ but no difference in discharge rates was observed in the $>55$ cohort (OR: $0.94,95 \% \mathrm{CI}: 0.78,1.15, \mathrm{p}=0.57$ ).

\section{Conclusions}

Women who suffer OHCAs have lower rates of survival and have unfavourable Utstein predictors. When survival is adjusted for these predictors survival is similar between men and women except in younger women suggesting that age modifies the association of gender and 
56 survival from OHCA; a result that supports a protective hormonal effect among premenopausal

57 women.

58

59

60

61

62

63 64
Key words: heart arrest; out of hospital cardiac arrest; cardiopulmonary resuscitation; gender; adult population 


\section{Background}

65 The median incidence of cardiac arrest treated by Emergency Medical Services (EMS), across

8

Certain medical conditions/diseases have gender ${ }^{1}$-based predominance due to specific hormonal regulation. ${ }^{2-10}$ Furthermore gender disparities in access to care have been observed previously at many different levels of care, including primary, acute and chronic care. ${ }^{11-21}$ For example, women are more likely to have a diagnosis of myocardial infarction missed in the Emergency Department, and are less likely to receive invasive diagnostic testing and treatments for cardiovascular diseases, such as cardiac catheterization and percutaneous coronary intervention all of which might account for poorer outcomes and increased mortality. $5,17,22-27$

Previous research on age and gender-based out of hospital cardiac arrest (OHCA) has shown contradictory findings. ${ }^{2,3,6,28-32}$ Kannel et al., reported lower rates of sudden cardiac arrest in women when compared to men. ${ }^{28}$ Although one study ${ }^{2}$ has reported that female gender was associated with an increased survival rate from OHCA, many studies have demonstrated that women have unfavourable outcomes in cardiac arrest with significantly lower unadjusted

\footnotetext{
${ }^{1}$ As per the WHO definition, "Gender" refers to the socially constructed roles, behaviors, activities and attributes a given society considers appropriate for men and women (http://www.who.int/gender/whatisgender/en/index.html)
} 
84 survival rates than men. ${ }^{31,33-35}$ These contradictory findings represent significant gaps in the epidemiology of OHCA and merit further investigation.

87 Our study objective was to use a large North American population based research quality database of sequential cases of OHCA to describe the relationship between gender, age and outcomes (survival to hospital discharge) of OHCA patients and to stratify in two age cohorts ${ }^{8}$ to further investigate the potential impact of female reproductive hormones on survival outcomes. Considering the average age of first menarche in United States is 13 years ${ }^{36}$ and the average age of menopause is 50 years $^{37}$ we have assumed that women in a younger age cohort (15-45 yo) would have a high concentration of female reproductive hormones and would more likely have

94 favourable survival outcomes compared to men of the same age.

95

96

97

98

\section{Methods}

99

Design

100 The Resuscitation Outcomes Consortium (ROC) Epistry-Cardiac Arrest registry is a 101 prospective, population-based, multicentre, North American cohort study of non-traumatic

102 OHCA. ${ }^{38,39}$ The ROC Epistry Study met the requirements for minimal risk research in the 103 United States ${ }^{40}$ and Canada ${ }^{41}$ and was approved for waiver of informed consent by 161 104 institutional research ethics boards.

105

106 Setting 
ROC is a North American network of 10 US and Canadian sites that investigate OHCA (Figure 1). ROC has one data coordinating centre and more than 260 participating EMS agencies serving approximately 23.7 million persons. ${ }^{39}$

\section{Study population}

All eligible, consecutive, non-traumatic OHCA patients enrolled in the ROC Epistry between December 2005 and May 2007, prior to the start of the ROC intervention trials, were included. Eligible patients included individuals who experienced OHCA, and were evaluated and received attempted resuscitation by a participating ROC-affiliated EMS agency. Treated cardiac arrest was defined as external defibrillation (by lay responders or EMS personnel), or chest compressions delivered by EMS personnel. We excluded persons who were obviously dead and did not receive cardiopulmonary resuscitation $(\mathrm{CPR})$ or defibrillation attempts. ${ }^{38}$

\section{Data Definitions}

The ROC Epistry-Cardiac Arrest database, data elements and quality assurance have been previously published. ${ }^{38}$ Uniform data definitions were based on the Utstein elements. ${ }^{38,42-45}$ The Utstein elements include variables that are associated with survival; younger age, public location of the arrest, witnessed event (bystander or EMS witnessed), bystander CPR, a shockable (Ventricular Tachycardia or Ventricular Fibrillation) initial cardiac rhythm recorded by EMS personnel, and a short EMS response time interval. The quality of CPR process measures were compared across gender and age. If no obvious cause (for example opioid overdose, strangulation, drowning) of OHCA is determined based on review of the source documents, cardiac arrest was assumed to be of cardiac origin and eligible. The primary outcome was 
survival to hospital discharge as functional survival was not captured at this time. The secondary outcomes included death in the field, return of spontaneous circulation (ROSC) and sustained ROSC on arrival at the hospital. Patient age was analyzed as a continuous variable and a categorical variable ( $<21$ years, $21-30,31-40,41-50,51-60,61-70,>70)$. To further separate the groups by hormonal status, patients were stratified in two age cohorts ${ }^{8}$ : younger women of childbearing age 15-45 years of age (yoa) and post-menopausal women $>55$ yoa ${ }^{8}$.

\section{Statistical Analysis}

Baseline characteristics were examined for all treated cases and stratified by gender and by age and by the age-gender interaction. Data were reported as means (standard deviation (SD)), medians ( $15 \%$ and $75 \%$ interquartile range (IQR)), numbers (percent) or as proportions.. Unadjusted Chi-Square tests were performed to examine differences in outcome across either gender or age. Unadjusted cardiac arrest event incidence rates (n per 100,000 person/year) were calculated by gender for each site in the study. Our approach included calculating the closed population of the geographical footprint served by each participating EMS service for the 20062007 year period based on 2000 US Census and 2006 StatCan. We employed multivariable logistic regression to assess the association between gender and outcome across age. Results are presented as Odds Ratios (with 95\% Confidence Intervals). Data management and analysis was performed in S-PLUS (version 6.2.1), c (2003), Insightful Corporation, Seattle, WA.

\section{Results}

This study of 14,690 consecutive patients treated by EMS included 5,340 (36.4\%) women with a mean age of 68.3 and 9,350 (63.6\%) men with a mean age of 64.2. (Figure 1 and Table 1) The 
unadjusted incidence rate of treated OHCA for women ranged from 34 to 104 per 100,000 person years (median 41) across ROC sites while for men it ranged from 64 to 123 per 100000 person years (median 85).

Event characteristics are displayed in Table 1. Many of the Utstein predictors of survival are more likely to be associated with men. Women are more likely to suffer an unwitnessed OHCA in a private setting $(\mathrm{p}<0.001)$ and less likely to receive bystander CPR or AED use $(\mathrm{p}<0.001)$, and their initial rhythm is less likely to be shockable $(\mathrm{p}<0.001)$. Table 1 There were no statistically significant differences based on process measures in CPR delivered to women vs. men suffering from OHCA.(Table 2).

The primary and secondary outcomes are reported in Table 3. The inclusion of the age-gender interactions was not significant and thus excluded from the final model (Table 4). The difference in survival rates between women and men did not reach statistical significance after adjustment for all Utstein predictors (OR: 1.16, 95\%CI: 0.98, 1.36) (Table 5).However, despite the lack of favourable Utstein elements in the prehospital setting women of all ages were more likely to achieve ROSC when compared to men in the adjusted analysis. (Table 5). When adjusted for common Utstein predictors, women survived to discharge at a significantly higher rate $(\mathrm{p}=0.03)$ than men in the $15-45$ yo cohort (OR: $1.66,95 \% \mathrm{CI}: 1.04,2.64)$ but no significant difference in discharge rates was observed in the $>55$ cohort (OR: 0.94, 95\%CI: $0.78,1.15$ ) (Table 5).

\section{Discussion}


Data from a prospective, North American multisite population-based database of OHCA patients attended by participating EMS agencies suggests that women who suffer an OHCA are less likely to experience event characteristics associated with survival and less likely to survive. When survival is adjusted for this imbalance in predictors of outcome, women are more likely to obtain a ROSC in the prehospital setting but the gender difference in survival to discharge disappears. However, in women between the ages of 15-45 their adjusted survival is better than men of the same age suggesting a protective effect of hormonal levels in this cohort of patients.

Survival outcomes from OHCA are generally poor with the survival-to-discharge rates across the ROC sites varied from of $3.0 \%$ to $16.3 \%$. ${ }^{1}$ Many studies have reported that survival outcomes differ across gender and the findings were somewhat contradictory. ${ }^{2,3,6,28-32}$ Survival outcomes also differed across genders in our study. The rate of return of spontaneous circulation at any time in the prehospital setting was not significantly different between women and men in the unadjusted analysis. Women had higher adjusted rates of return of spontaneous circulation than men in the prehospital setting, similar to previous studies that reported higher prehospital resuscitation rates for women. ${ }^{2-4,7,31}$ This was an interesting finding given that women have lower rates of all of the favourable Utstein elements.

In contrast to previous European studies ${ }^{2,4,31}$ who reported that women were more likely to survive to admission and less likely to die in the field, our data showed that women died in the field at significantly higher rates compared to men (40.0\% vs. $36.2 \%$, possibly due to lower rates of favourable Utstein elements in arrest events associated with women. Compared to previous studies in which, results were adjusted for some but not all confounders, ${ }^{2,4,31}$ we fully accounted 
198 for Utstein variables in the analysis. Other potential explanations for discrepancy in the results

199 may include other factors that limit generalizability of the previous studies such as different race 200 composition, locations (urban vs. semi-urban/rural).

202 Survival rates to hospital discharge of OHCA differ between men and women as well. Although 203 women survived to hospital discharge less often than men (6.4\% vs. $9.1 \%)$ in an unadjusted 204 comparison, this difference appears to be confounded by several Utstein factors. When survival 205 across genders is adjusted for all the Utstein variables including the Utstein variables which 206 favour survival and are more often reported in men, the difference in survival disappears. While 207 some studies have demonstrated similar survival to hospital discharge outcomes, ${ }^{3,4,31}$ others 208 have reported lower survival to hospital discharge rates for women., ${ }^{40,46}$ Pell et al., ${ }^{4}$ and Perers 209 et al., ${ }^{30}$ concluded lower survival to discharge rates for women; however, they employed 210 incomplete adjustment for all relevant Utstein variables.

212 Previous studies have shown that gender-based predominance and specific hormonal regulation 213 are associated with certain medical conditions/diseases and their clinical outcomes. ${ }^{2-10}$ Kitamura 214 and his group has demonstrated that women aged 13-49 years had a significantly lower incidence 215 and a better outcome after OHCA compared to men in the same age cohort. ${ }^{9}$ Topjian et al., ${ }^{8}$ who 216 studied in-hospital cardiac arrest has shown that women of child-bearing age (15-44 years of 217 age) were more likely to survive to hospital discharge than men. ${ }^{8}$ Both groups have speculated 218 that this difference might be explained by potential cardioprotective effects of female sex 219 hormones $^{8,9}$ and our results lend further support to that speculation. Although the epidemiology 
and outcomes from OHCA and in-hospital cardiac arrest differ, improved survival outcomes for women in the child-bearing age group is a consistent finding across the studies. ${ }^{8,9}$

An extensive body of experimental and clinical data support the hypothesis that female sex hormones may improve the clinical outcomes from global cerebral hypoxic-ischemic insults. ${ }^{47-57}$ Many studies have sought to propose the mechanisms of action. ${ }^{50,53,54,56,57}$ While some studies have reported that estrogen may affect and decrease activation of inflammation cascade and apoptotic signaling pathway, ${ }^{53,54}$ another study identified a positive effect of estrogen on the signaling of protective pathways and decrease of brain ischemic secondary injury ${ }^{54}$ Using a mouse model of cardiac arrest and CPR, long-term administration of estrogen was neuroprotective and that effect was most likely mediated through ER-[beta]. ${ }^{50}$ Hutchens et al.. ${ }^{57}$ have reported that in female mice who underwent cardiac arrest and CPR, kidneys were protected from cardiac arrest through estrogen effect and that renoprotection was estrogen receptor ER-[alpha] and ER-[beta] independent. ${ }^{57}$ Having a receptor-site independent effect would make estrogen more beneficial across genders. To date, there are no human interventional trials testing the administration of estrogen or progesterone in cardiac arrest population.

The ROC Epistry-Cardiac Arrest data analysis was limited in its ability to account for variability in in-hospital post arrest care across multiple institutions and its effect on OHCA outcomes. Quality post arrest care includes the implementation of a comprehensive, multidisciplinary system of care with structured interventions. Of these only targeted temperature management has been shown to affect outcome; ${ }^{58,59}$ however, it is conceivable that differences in-hospital 
242 care may lead to differences in long-term survival rates ${ }^{60-63}$ after cardiac arrest, hence in future

243 studies it is important to assess the impact of post arrest care on OHCA outcomes.

244

245

246

247

248

249

250

251

252

253

254

255

256

257

258

259

260

261

262

263

264

\section{Conclusion}

Women who suffer an OHCA are less likely to have Utstein event characteristics associated with survival such as arresting in a public location or an initial shockable rhythm or bystander resuscitation and have a lower rate of survival to discharge. After adjusting for the imbalance in these predictors, there was no observed gender difference in survival. As in other studies, women in the 15-45 year old cohort had a higher survival rate than men, a protective hormonal effect among premenopausal women. Further elucidation of the underlying mechanisms for the survival benefit of younger women may lead to new treatment strategies and improved outcomes for women who suffer an OHCA.

\section{Acknowledgements}

The ROC is supported by a series of cooperative agreements to 10 regional clinical centers and one Data Coordinating Center (5U01 HL077863-University of Washington Data Coordinating Center, HL077865-University of Iowa, HL077866-Medical College of Wisconsin, HL077867University of Washington, HL077871-University of Pittsburgh, HL077872-St.

Michael's Hospital, HL077873-Oregon Health and Science University, HL077881-University of Alabama at Birmingham, HL077885-Ottawa Hospital Research Institute, HL077887-University of Texas SW Medical Ctr/Dallas, HL077908-University of California San Diego) from the National Heart, Lung and Blood Institute in partnership with the National Institute of Neurological Disorders and Stroke, U.S. Army Medical Research \& Material Command, The 
265 Canadian Institutes of Health Research (CIHR) - Institute of Circulatory and Respiratory Health, 266 Defence Research and Development Canada, the Heart, Stroke Foundation of Canada and the 267 American Heart Association. The content is solely the responsibility of the authors and does not 268 necessarily represent the official views of the National Heart, Lung and Blood Institute or the 269 National Institutes of Health. 


\section{Bibliography}

1. Nichol G, Thomas E, Callaway CW, Hedges J, Powell JL, Aufderheide TP, Rea T, Lowe R, Brown T, Dreyer J, Davis D, Idris A, Stiell I and Resuscitation Outcomes Consortium I. Regional variation in out-of-hospital cardiac arrest incidence and outcome. JAMA : the journal of the American Medical Association. 2008;300:1423-31.

2. Herlitz J, Engdahl J, Svensson L, Young M, Angquist KA and Holmberg S. Is female sex associated with increased survival after out-of-hospital cardiac arrest? Resuscitation. 2004;60:197-203.

3. Kim C, Fahrenbruch CE, Cobb LA and Eisenberg MS. Out-of-hospital cardiac arrest in men and women. Circulation. 2001;104:2699-703.

4. Pell JP, Sirel J, Marsden AK and Cobbe SM. Sex differences in outcome following communitybased cardiopulmonary arrest. Eur Heart J. 2000;21:239-44.

5. Tunstall-Pedoe H, Morrison C, Woodward M, Fitzpatrick B and Watt G. Sex differences in myocardial infarction and coronary deaths in the Scottish MONICA population of Glasgow 1985 to 1991. Presentation, diagnosis, treatment, and 28-day case fatality of 3991 events in men and 1551 events in women. Circulation. 1996;93:1981-92.

6. Vukmir RB. Prehospital cardiac arrest and the adverse effect of male gender, but not age, on outcome. $J$ Womens Health (Larchmt). 2003;12:667-73.

7. Wigginton JG, Pepe PE, Bedolla JP, DeTamble LA and Atkins JM. Sex-related differences in the presentation and outcome of out-of-hospital cardiopulmonary arrest: a multiyear, prospective, populationbased study. Crit Care Med. 2002;30:S131-6.

8. Topjian AA, Localio AR, Berg RA, Alessandrini EA, Meaney PA, Pepe PE, Larkin GL, Peberdy MA, Becker LB and Nadkarni VM. Women of child-bearing age have better inhospital cardiac arrest survival outcomes than do equal-aged men. Crit Care Med. 2010;38:1254-60.

9. Kitamura T, Iwami T, Nichol G, Nishiuchi T, Hayashi Y, Nishiyama C, Sakai T, Kajino K, Hiraide A, Ikeuchi H, Nonogi $\mathrm{H}$ and Kawamura T. Reduction in incidence and fatality of out-of-hospital cardiac arrest in females of the reproductive age. Eur Heart J. 2010;31:1365-72.

10. Gowda RM, Wilbur SL and Schweitzer P. Gender differences in cardiac electrophysiology and arrhythmias. Part 1. Kardiologia. 2006;15:296-302.

11. Bierman AS, Jaakkimainen RL, Abramson B, Kapral MK, Azad N, Hall R, Lindsay P, Honein G and N. D. Cardiovascular Diseases. In: Bierman AS, editor. Project for an Ontario Women's Health Evidence-Based Report. 2009;1.

12. Bierman AS, Angus J, Ahmad f, Degani N, Vahabi M, Glazier RH, Li Y, Ross S and D. M. Access to Health Care Services. In: Bierman AS, editor. Project for an Ontario Women's Health EvidenceBased Report. 2009;1.

13. Birnie DH, Sambell C, Johansen H, Williams K, Lemery R, Green MS, Gollob MH, Lee DS and Tang AS. Use of implantable cardioverter defibrillators in Canadian and US survivors of out-of-hospital cardiac arrest. CMAJ. 2007;177:41-6.

14. Fowler RA, Sabur N, Li P, Juurlink DN, Pinto R, Hladunewich MA, Adhikari NK, Sibbald WJ and Martin CM. Sex-and age-based differences in the delivery and outcomes of critical care. CMAJ. 2007;177:1513-9.

15. Franconi F, Campesi I, Occhioni S and Tonolo G. Sex-Gender Differences in Diabetes Vascular Complications and Treatment. Endocr Metab Immune Disord Drug Targets. 2012.

16. Goddard $\mathrm{M}$ and Smith P. Equity of access to health care services: theory and evidence from the UK. Soc Sci Med. 2001;53:1149-62.

17. Poon S, Goodman SG, Yan RT, Bugiardini R, Bierman AS, Eagle KA, Johnston N, Huynh T, Grondin FR, Schenck-Gustafsson K and Yan AT. Bridging the gender gap: Insights from a contemporary analysis of sex-related differences in the treatment and outcomes of patients with acute coronary syndromes. Am Heart J. 2011;163:66-73.

18. Ng JH, Kaftarian SJ, Tilson WM, Gorrell P, Chen X, Chesley FD, Jr. and Scholle SH. Selfreported delays in receipt of health care among women with diabetes and cardiovascular conditions. Womens Health Issues. 2010;20:316-22. 
19. Brannstrom J, Hamberg K, Molander L, Lovheim H and Gustafson Y. Gender disparities in the pharmacological treatment of cardiovascular disease and diabetes mellitus in the very old: an epidemiological, cross-sectional survey. Drugs Aging. 2011;28:993-1005.

20. Curtis AB. Are women worldwide under-treated with regard to cardiac resynchronization and sudden death prevention?. [Review] [28 refs]. Journal of Interventional Cardiac Electrophysiology. 2006;17:169-175.

21. Curtis LH, Al-Khatib SM, Shea AM, Hammill BG, Hernandez AF and Schulman KA. Sex differences in the use of implantable cardioverter-defibrillators for primary and secondary prevention of sudden cardiac death. JAMA. 2007;298:1517-1524.

22. Tavris D, Shoaibi A, Chen AY, Uchida T, Roe MT and Chen J. Gender differences in the treatment of non-ST-segment elevation myocardial infarction. Clin Cardiol. 2010;33:99-103.

23. Hollenbeak C WC, Rossi M, Ettinger S. Gender Disparities in Percutaneous Coronary Interventions for Acute Myocardial Infarction in Pennsylvania. AcademyHealth Meeting 2005.

24. Hollenbeak CS, Weisman CS, Rossi M and Ettinger SM. Gender disparities in percutaneous coronary interventions for acute myocardial infarction in Pennsylvania. Med Care. 2006;44:24-30.

25. Sonke GS, Beaglehole R, Stewart AW, Jackson R and Stewart FM. Sex differences in case fatality before and after admission to hospital after acute cardiac events: analysis of community based coronary heart disease register. BMJ. 1996;313:853-5.

26. Vaccarino V, Horwitz RI, Meehan TP, Petrillo MK, Radford MJ and Krumholz HM. Sex differences in mortality after myocardial infarction: evidence for a sex-age interaction. Arch Intern Med. $1998 ; 158: 2054-62$.

27. Vaccarino V, Parsons L, Every NR, Barron HV and Krumholz HM. Sex-based differences in early mortality after myocardial infarction. National Registry of Myocardial Infarction 2 Participants. $N$ Engl $J$ Med. 1999;341:217-25.

28. Kannel WB and McGee DL. Epidemiology of sudden death: insights from the Framingham Study. Cardiovasc Clin. 1985; 15:93-105.

29. Kannel WB and Schatzkin A. Sudden death: lessons from subsets in population studies. $J$ Am Coll Cardiol. 1985;5:141B-149B.

30. Perers E, Abrahamsson P, Bang A, Engdahl J, Karlson BW, Lindqvist J, Waagstein L and Herlitz J. Outcomes of patients hospitalized after out-of-hospital cardiac arrest in relation to sex. Coron Artery Dis. 1999;10:509-14.

31. Perers E, Abrahamsson P, Bang A, Engdahl J, Lindqvist J, Karlson BW, Waagstein L and Herlitz $\mathrm{J}$. There is a difference in characteristics and outcome between women and men who suffer out of hospital cardiac arrest. Resuscitation. 1999;40:133-40.

32. Arrich J, Sterz F, Fleischhackl R, Uray T, Losert H, Kliegel A, Wandaller C, Kohler K and Laggner AN. Gender modifies the influence of age on outcome after successfully resuscitated cardiac arrest: a retrospective cohort study. Medicine (Baltimore). 2006;85:288-94.

33. Ritter G, Wolfe RA, Goldstein S, Landis JR, Vasu CM, Acheson A, Leighton R and Medendrop

$\mathrm{SV}$. The effect of bystander CPR on survival of out-of-hospital cardiac arrest victims. Am Heart J. 1985;110:932-7.

34. Hallstrom AP, Cobb LA, Swain M and Mensinger K. Predictors of hospital mortality after out-ofhospital cardiopulmonary resuscitation. Crit Care Med. 1985;13:927-9.

35. Weston CF, Wilson RJ and Jones SD. Predicting survival from out-of-hospital cardiac arrest: a multivariate analysis. Resuscitation. 1997;34:27-34.

36. Anderson SE, Dallal GE and Must A. Relative weight and race influence average age at menarche: results from two nationally representative surveys of US girls studied 25 years apart. Pediatrics. 2003;111:844-50.

37. McKinlay SM, Brambilla DJ and Posner JG. The normal menopause transition. Maturitas. 1992;14:103-15.

38. Morrison LJ, Nichol G, Rea TD, Christenson J, Callaway CW, Stephens S, Pirrallo RG, Atkins DL, Davis DP, Idris AH, Newgard C and Investigators ROC. Rationale, development and implementation of the Resuscitation Outcomes Consortium Epistry-Cardiac Arrest. Resuscitation. 2008;78:161-9.

39. Davis DP, Garberson LA, Andrusiek DL, Hostler D, Daya M, Pirrallo R, Craig A, Stephens S, Larsen J, Drum AF and Fowler R. A descriptive analysis of Emergency Medical Service Systems participating in the Resuscitation Outcomes Consortium (ROC) network. Prehospital emergency care: 
official journal of the National Association of EMS Physicians and the National Association of State EMS Directors. 2007;11:369-82.

40. Food and Drug Administration. Protection of human subjects; informed consent--FDA. Final rule. Fed Regist. 1996;61:51498-533.

41. Canadian Institutes of Health Research, Natural Sciences and Engineering Research Council of Canada and and Social Sciences and Humanities Research Council of Canada. Tri-Council Policy Statement: Ethical Conduct for Research Involving Humans. December 2010.

42. Jacobs I, Nadkarni V, Bahr J, Berg RA, Billi JE, Bossaert L, Cassan P, Coovadia A, D'Este K, Finn J, Halperin H, Handley A, Herlitz J, Hickey R, Idris A, Kloeck W, Larkin GL, Mancini ME, Mason P, Mears G, Monsieurs K, Montgomery W, Morley P, Nichol G, Nolan J, Okada K, Perlman J, Shuster M, Steen PA, Sterz F, Tibballs J, Timerman S, Truitt T, Zideman D, International Liaison Committee on R, American Heart A, European Resuscitation C, Australian Resuscitation C, New Zealand Resuscitation C, Heart, Stroke Foundation of C, InterAmerican Heart F, Resuscitation Councils of Southern A, Arrest ITFoC and Cardiopulmonary Resuscitation O. Cardiac arrest and cardiopulmonary resuscitation outcome reports: update and simplification of the Utstein templates for resuscitation registries: a statement for healthcare professionals from a task force of the International Liaison Committee on Resuscitation (American Heart Association, European Resuscitation Council, Australian Resuscitation Council, New Zealand Resuscitation Council, Heart and Stroke Foundation of Canada, InterAmerican Heart Foundation, Resuscitation Councils of Southern Africa). Circulation. 2004;110:3385-97.

43. Jacobs I and Nadkarni V. Utstein cardiac arrest outcome reports. Resuscitation. 2009;80:290.

44. Rea TD, Cook AJ, Stiell IG, Powell J, Bigham B, Callaway CW, Chugh S, Aufderheide TP, Morrison L, Terndrup TE, Beaudoin T, Wittwer L, Davis D, Idris A and Nichol G. Predicting survival after out-of-hospital cardiac arrest: role of the Utstein data elements. Ann Emerg Med. 2009;55:249-57.

45. Peberdy MA, Cretikos M, Abella BS, DeVita M, Goldhill D, Kloeck W, Kronick SL, Morrison LJ, Nadkarni VM, Nichol G, Nolan JP, Parr M, Tibballs J, van der Jagt EW and Young L. Recommended guidelines for monitoring, reporting, and conducting research on medical emergency team, outreach, and rapid response systems: an Utstein-style scientific statement: a scientific statement from the International Liaison Committee on Resuscitation (American Heart Association, Australian Resuscitation Council, European Resuscitation Council, Heart and Stroke Foundation of Canada, InterAmerican Heart Foundation, Resuscitation Council of Southern Africa, and the New Zealand Resuscitation Council); the American Heart Association Emergency Cardiovascular Care Committee; the Council on Cardiopulmonary, Perioperative, and Critical Care; and the Interdisciplinary Working Group on Quality of Care and Outcomes Research. Circulation. 2007;116:2481-500.

46. Akahane M, Ogawa T, Koike S, Tanabe S, Horiguchi H, Mizoguchi T, Yasunaga H and Imamura T. The effects of sex on out-of-hospital cardiac arrest outcomes. Am J Med. 2011;124:325-33.

47. Cervantes M, Gonzalez-Vidal MD, Ruelas R, Escobar A and Morali G. Neuroprotective effects of progesterone on damage elicited by acute global cerebral ischemia in neurons of the caudate nucleus. Arch Med Res. 2002;33:6-14.

48. Ishrat T, Sayeed I, Atif F and Stein DG. Effects of progesterone administration on infarct volume and functional deficits following permanent focal cerebral ischemia in rats. Brain Res. 2009;1257:94-101. 49. Jover T, Tanaka H, Calderone A, Oguro K, Bennett MV, Etgen AM and Zukin RS. Estrogen protects against global ischemia-induced neuronal death and prevents activation of apoptotic signaling cascades in the hippocampal CA1. J Neurosci. 2002;22:2115-24.

50. Noppens RR, Kofler J, Grafe MR, Hurn PD and Traystman RJ. Estradiol after cardiac arrest and cardiopulmonary resuscitation is neuroprotective and mediated through estrogen receptor-beta. J Cereb Blood Flow Metab. 2009;29:277-86.

51. Xiao G, Wei J, Yan W, Wang W and Lu Z. Improved outcomes from the administration of progesterone for patients with acute severe traumatic brain injury: a randomized controlled trial. Crit Care. 2008; 12:R61.

52. Wigginton JG, Pepe PE and Idris AH. Rationale for routine and immediate administration of intravenous estrogen for all critically ill and injured patients. Crit Care Med. 2011;38:S620-9.

53. Gatson JW, Maass DL, Simpkins JW, Idris AH, Minei JP and Wigginton JG. Estrogen treatment following severe burn injury reduces brain inflammation and apoptotic signaling. J Neuroinflammation. $2009 ; 6: 30$.

54. Gatson J, Liu MM, Abdelfattah K, Wigginton JG, Smith S, Wolf SE, Simpkins JW and Minei JP. Estrone is Neuroprotective in Rats Following Traumatic Brain Injury. J Neurotrauma. 2012. 
55. Wigginton JG, Roppolo L and Pepe PE. Advances in resuscitative trauma care. Minerva Anestesiol. 2011;77:993-1002.

56. Gatson JW, Simpkins JW, Yi KD, Idris AH, Minei JP and Wigginton JG. Aromatase is increased in astrocytes in the presence of elevated pressure. Endocrinology. 2010;152:207-13.

57. Hutchens MP, Nakano T, Kosaka Y, Dunlap J, Zhang W, Herson PS, Murphy SJ, Anderson S and Hurn PD. Estrogen is renoprotective via a nonreceptor-dependent mechanism after cardiac arrest in vivo. Anesthesiology. 2010;112:395-405.

58. Peberdy MA, Callaway CW, Neumar RW, Geocadin RG, Zimmerman JL, Donnino M, Gabrielli A, Silvers SM, Zaritsky AL, Merchant R, Vanden Hoek TL, Kronick SL and American Heart A. Part 9: post-cardiac arrest care: 2010 American Heart Association Guidelines for Cardiopulmonary Resuscitation and Emergency Cardiovascular Care. Circulation. 2010;122:S768-86.

59. Castren M, Silfvast T, Rubertsson S, Niskanen M, Valsson F, Wanscher M and Sunde K. Scandinavian clinical practice guidelines for therapeutic hypothermia and post-resuscitation care after cardiac arrest. Acta Anaesthesiol Scand. 2009;53:280-8.

60. Dumas F, Cariou A, Manzo-Silberman S, Grimaldi D, Vivien B, Rosencher J, Empana JP, Carli P, Mira JP, Jouven X and Spaulding C. Immediate percutaneous coronary intervention is associated with better survival after out-of-hospital cardiac arrest: insights from the PROCAT (Parisian Region Out of hospital Cardiac ArresT) registry. Circ Cardiovasc Interv. 2010;3:200-7.

61. Martinell L, Larsson M, Bang A, Karlsson T, Lindqvist J, Thoren AB and Herlitz J. Survival in out-of-hospital cardiac arrest before and after use of advanced postresuscitation care: a survey focusing on incidence, patient characteristics, survival, and estimated cerebral function after postresuscitation care. $\mathrm{Am}$ J Emerg Med. 2010;28:543-51.

62. Sunde K, Pytte M, Jacobsen D, Mangschau A, Jensen LP, Smedsrud C, Draegni T and Steen PA. Implementation of a standardised treatment protocol for post resuscitation care after out-of-hospital cardiac arrest. Resuscitation. 2007;73:29-39.

63. Sunde K and Soreide E. Therapeutic hypothermia after cardiac arrest: where are we now? Curr Opin Crit Care. 2011;17:247-53. 
Figure 1. Consort Diagram

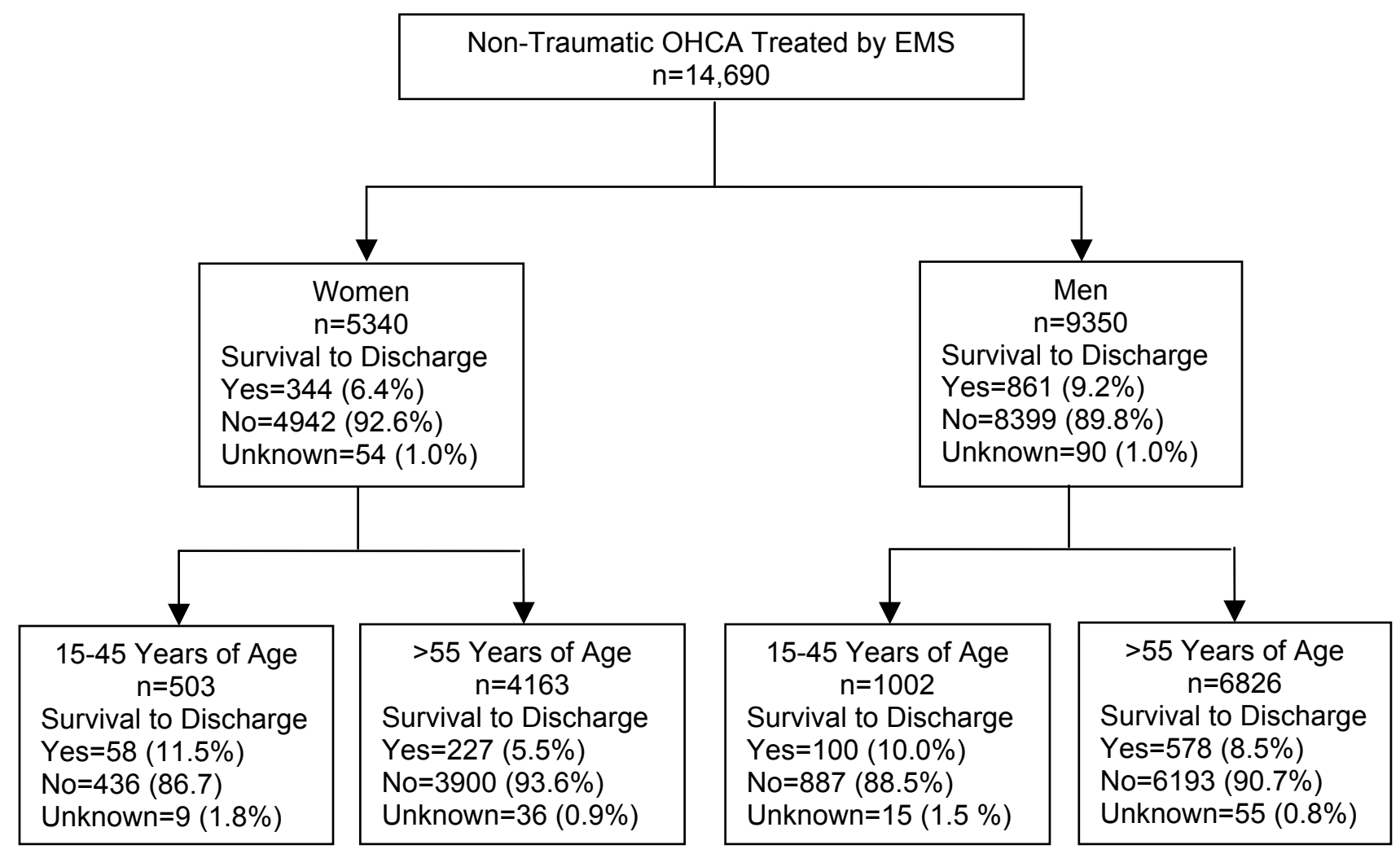


Table 1. Baseline Patient Characteristics and Utstein Predictors by Gender

\begin{tabular}{|c|c|c|c|}
\hline & Women & Men & $p$ value \\
\hline $\mathrm{n}(\%)$ & $5340(36.4)$ & $9350(63.6)$ & \\
\hline Median Age (IQR) & $73(24)$ & $66(25)$ & ns \\
\hline \multicolumn{4}{|l|}{ Location } \\
\hline Public, n(\%) & $424(7.9)$ & $1917(20.5)$ & $<0.001$ \\
\hline Private, $\mathrm{n}(\%)$ & $4913(92.0)$ & $7423(79.4)$ & $<0.001$ \\
\hline \multicolumn{4}{|l|}{ Initial Rhythm } \\
\hline Ventricular Tachycardia or Fibrillation, $\mathrm{n}(\%)$ & $887(16.6)$ & $2804(30.0)$ & $<0.001$ \\
\hline Asystole, $\mathrm{n}(\%)$ & $1162(21.8)$ & $1672(17.9)$ & ns \\
\hline Pulseless Electrical Activity, n(\%) & $2346(43.9)$ & $3422(36.6)$ & ns \\
\hline AED No Shock, n(\%) & $547(10.2)$ & $772(8.3)$ & ns \\
\hline Cannot Determine, $\mathrm{n}(\%)$ & $234(4.4)$ & $348(3.7)$ & ns \\
\hline \multicolumn{4}{|l|}{ Witnessed Status } \\
\hline Emergency Medical Services personnel, $\mathrm{n}(\%)$ & $535(10.0)$ & $756(8.1)$ & ns \\
\hline Bystander, $\mathrm{n}(\%)$ & $1834(34.3)$ & $3909(41.8)$ & ns \\
\hline None, $\mathrm{n}(\%)$ & $2444(45.8)$ & $3929(42.0)$ & ns \\
\hline Unknown, n(\%) & $527(9.9)$ & $756(8.1)$ & ns \\
\hline \multicolumn{4}{|l|}{ Bystander CPR Status } \\
\hline AED Shock, n(\%) & $54(1.0)$ & $169(1.8)$ & $<0.001$ \\
\hline AED Applied No Shock, n(\%) & $52(1.0)$ & $79(0.8)$ & $<0.001$ \\
\hline CPR Attempted No AED, n(\%) & $1578(29.6)$ & $2898(31.0)$ & $<0.001$ \\
\hline No Resuscitation, n(\%) & $3052(57.2)$ & $5204(55.7)$ & ns \\
\hline Unknown, n(\%) & $575(10.8)$ & $959(10.3)$ & ns \\
\hline Median EMS ResponseTime Interval (IQR) & $5.3(2.9)$ & $5.3(2.9)$ & ns \\
\hline
\end{tabular}


Table 2. CPR Process Measures by Gender

\begin{tabular}{|c|c|c|c|}
\hline & Women & Men & $\mathrm{p}$ value \\
\hline $\mathrm{N}^{*}$ & 1090 & 2190 & ns \\
\hline Mean \# CPR Process Minutes (sd) & $5.8(2.6)$ & $6.0(2.6)$ & \\
\hline \multicolumn{4}{|l|}{ Compression Rate } \\
\hline Mean (sd) & $107.2(22.5)$ & $108.0(21.8)$ & ns \\
\hline Out of Range $(<80$ or $>120)$ & $274(34.6)$ & $524(33.7)$ & ns \\
\hline \multicolumn{4}{|l|}{ CPR Fraction } \\
\hline Mean (sd) & $0.68(0.2)$ & $0.67(0.2)$ & ns \\
\hline Out of Range $(<0.50)$ & $134(16.9)$ & $294(18.9)$ & ns \\
\hline \multicolumn{4}{|l|}{ Ventilation Rate } \\
\hline Mean (sd) & $5.5(4.3)$ & $4.8(3.9)$ & ns \\
\hline Out of Range $(<4$ or $>8)$ & $85(62.0)$ & $160(71.7)$ & ns \\
\hline \multicolumn{4}{|l|}{ Compression Depth } \\
\hline Mean $(\mathrm{sd})$ & $36.0(10.5)$ & $37.2(10.3)$ & ns \\
\hline \multicolumn{4}{|l|}{ Number of defibrillation shocks } \\
\hline Mean (sd) & $3.0(2.6)$ & $3.5(3.0)$ & ns \\
\hline
\end{tabular}

* - number with at least 1 minute of CPR Process data

Legend: CPR; cardiopulmonary resuscitation, sd: standard deviation, 
Table 3 Primary and Secondary Outcomes

\begin{tabular}{lccc}
\hline & Women & Men & p value \\
\hline $\mathrm{n}(\%)$ & 5340 & 9350 & \\
Prehospital ROSC & $(36.4 \%)$ & $(63.6 \%)$ & \\
Sustained ROSC on arrival in the ED & $28.1 \%$ & $28.2 \%$ & $\mathrm{~ns}$ \\
Resuscitation terminated in the field & $52.5 \%$ & $53.7 \%$ & $\mathrm{~ns}$ \\
Survival to Discharge & $40 \%$ & $36.2 \%$ & $<0.001$ \\
\end{tabular}


Table 4. Adjusted Regression Estimates for Assessing Gender and Survival to Hospital Discharge and the Interaction of Age-Gender

\begin{tabular}{ll}
\hline Age Group & Odds Ratio $(95 \% \mathrm{Cl})$ \\
\hline Women & $1.16[0.98,1.36]$ \\
Initial Rhythm & \\
Non-shockable & $0.54[0.42,0.69]$ \\
Asystole & $0.62[0.55,0.70]$ \\
PEA & $1.00[0.94,1.07]$ \\
VTVF & $1.41[1.36,1.46]$ \\
Witness Status & \\
Bystander & $1.39[1.26,1.53]$ \\
EMS & $1.68[1.57,1.81]$ \\
Bystander CPR & $1.35[1.15,1.59]$ \\
ALS & $1.48[1.08,2.03]$ \\
Arrival Time & $0.93[0.90,0.96]$ \\
Public Location & $1.86[1.58,2.19]$ \\
Age (years) & \\
$21-30$ & $0.83[0.70,0.99]$ \\
$31-40$ & $0.98[0.90,1.06]$ \\
$41-50$ & $0.97[0.93,1.03]$ \\
$51-60$ & $0.96[0.93,1.00]$ \\
$61-70$ & $0.90[0.88,0.93]$ \\
$>70$ & $1.00[1.00,1.00]$ \\
\hline
\end{tabular}

Legend: PEA: Pulseless Electrical Activity, VT/VF: Ventricular Tachcardia/Ventricular Fibrillation, EMS: Emergency Medical Services, CPR; Cardiopulmonary Resuscitation; ALS; Advanced Life Support 
Table 5: Female Survival to Hospital Discharge Regression Estimates

\begin{tabular}{lcc} 
& \multicolumn{1}{c}{ Adjusted $^{*}$} & Unadjusted \\
\hline Survival to Hospital Discharge & OR $[95 \% \mathrm{Cl}]$ & \\
All & $1.16[0.98,1.36]$ & $0.64[0.56,0.72]$ \\
$15-45$ years & $1.61[1.02,2.53]$ & $1.29[0.93,1.81]$ \\
$>55$ years & $0.93[0.76,1.13]$ & $0.54[0.46,0.64]$ \\
\hline Any Prehospital ROSC & & \\
All & $1.31[1.19,1.43]$ & $0.91[0.85,0.97]$ \\
$15-45$ years & $1.34[0.99,1.80]$ & $1.22[0.97,1.53]$ \\
$>55$ years & $1.29[1.16,1.43]$ & $0.84[0.78,0.91]$ \\
\hline \hline
\end{tabular}

*Adjusted for initial rhythm, witness status, bystander cardiopulmonary

resuscitation, advance life support, response time interval, public location 